\title{
Penetrating abdominal injuries in an emerging semi- urban teaching hospital
}

\author{
Julius Gbenga Olaogun ${ }^{*}{ }^{*}$, Amarachukwu Chiduziem Etonyeaku², Joshua Taye Ige ${ }^{3}$, Obafemi Kayode \\ Wuraola ${ }^{3}$ \\ 'Department of Surgery, Ekiti State University, Ado-Ekiti, Nigeria \\ ${ }^{2}$ Department of Surgery, Obafemi Awolowo University Teaching Hospital, Obafemi Awolowo University, Ile-Ife, Nigeria \\ ${ }^{3}$ Department of Surgery, Ekiti State University Teaching Hospital, Ado-Ekiti, Nigeria
}

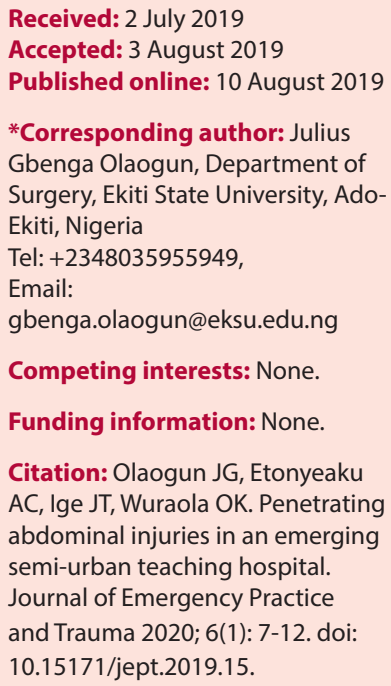

\begin{abstract}
Objective: There has been a worldwide rise in the prevalence of penetrating abdominal injury (PAI), and there are both inter-country and intra-country variations in frequencies. This study evaluates the mechanisms and pattern of penetrating abdominal injuries and the treatment outcome in our center.

Methods: This descriptive study of adult patients managed for PAI was conducted at the Ekiti State University Teaching Hospital (EKSUTH), Ado-Ekiti from January 2015 to December 2018. Data were prospectively collected and analyzed by using descriptive statistics from Statistical Package for Social Sciences (SPSS) version 20.0.

Results: There were 96 patients managed for abdominal injuries during the study period. Forty-six (47.9\%) of them had PAl, while $50(52.1 \%)$ others sustained blunt trauma. Patients ages ranged from 17-72 years (mean $=34.2 \pm 10.8$ years; median $=34$ years). Majority, 42 (91.3\%), were males, while 4 (8.7\%) were females ( $M: F=11: 1)$. The most afflicted age group was in the 4th decade. Majority of the injuries were due to gunshot (60.9\%) followed by stab $(26.1 \%)$, unsafe abortion (6.5\%), road traffic injury (4.3\%) and fall (2.2\%). Gastrointestinal injuries were the most common with small bowel perforations predominating. Solid organ injuries were only seen in $3(7.9 \%)$ patients. Eight $(17.4 \%)$ had associated extra-abdominal injuries. Thirty-eight (82.6\%) patients required exploratory laparotomy, while $8(17.4 \%)$ were managed non-operatively. The negative laparotomy rate was $2.6 \%$. Seven (15.2\%) patients developed complications which were mostly wound infection $(10.8 \%)$. The duration of hospital stay was $1-58$ days (mean $12.7 \pm 10.5$ ). Three patients $(6.5 \%)$ with gunshot injuries died.

Conclusion: Gunshot wounds were the major variant of PAl, and the highest cause of mortality from it. Gut injuries were most common, and exploratory laparotomy remains the main-stay of treatment, while non-operative management is practicable in carefully selected cases. Keywords: Penetrating abdominal injury, Pattern, Non-operative management, Laparotomy, Outcome, Nigeria
\end{abstract}

\section{Introduction}

Trauma is a major contributor to mortality and morbidity rates among the economically productive workforce of a population (1). Furthermore, it is of immense public health concern in both developed and developing countries as it impacts negatively on the economic indices of people. There is a worldwide increase in abdominal trauma, which on its own is a major contributor to trauma associated disabilities and deaths (2).

Trauma involving the abdominal region can either be blunt or penetrating. In Nigeria and other West African subregions, urbanization, high unemployment rate and poor economic indices have driven up crime rates. In addition to these, religious and political crises have led to increased rate of penetrating abdominal injuries (PAIs) (3-6). There appears to be a geographical and spatial variation in the incidence of PAI and the mechanism of injury, and this correlates with the level of urbanization, socio-political stressors and plethora of the weapons available among other factors. The nature of the weapon, the depth of penetration, the organ system affected and the energy transferred as the weapon traverses tissue impacts on the nature and severity of the injury, the kind of intervention needed and the likely outcome of such interventions. Thus, high energy impact injuries like gunshot are worse than stab wounds; single edge knife injuries are lesser 
than multiple edged objects. Similarly, injuries from bomb blasts are far worse than the aforementioned varieties. The management of PAI has been changing in the past couple of decades. Patients were traditionally managed by mandatory exploratory laparotomy for all cases; however, with advances in medical imaging, biomechanics and pathophysiology of injuries, a more flexible approach of non-operative care of some cases has been adopted (7). This is termed "selective non-operative management (SNOM)". The adoption of SNOM has been used for stab injuries; however, its applicability in the management of gunshot wounds involving the abdomen is controversial among surgeons in most trauma centers worldwide $(2,4,7,8)$. Even in the operative management, the need for primary closure, resection and anastomosis (with/without stapling devices or -ostomies) varies between individual patients and the attending surgeon.

This study focused on the mechanisms and nature of penetrating abdominal injuries, the characteristics of victims and the outcome of management of injured patients in our hospital.

\section{Methods}

Patients who sustained abdominal injuries and were seen at the emergency department of the hospital between January 1, 2015 and December 31,2018, were prospectively studied. A data sheet was used to gather information on the socio-demography of patients, presenting complaints, injury arrival time, patterns of injury and findings on clinical evaluation. Laboratory and radiologic tests were done as indicated and they included full blood count, blood grouping and cross matching, electrolytes, urea and creatinine, abdominopelvic scan and chest radiograph. No patient underwent computerized tomography (CT) due to the non-availability of this facility in our center. Patients were adequately resuscitated and the decision for emergency surgery or non-operative care was taken by the managing consultant after post resuscitation review. Indications for surgery were unstable haemodynamics, herniated abdominal content and obvious peritoneal signs consistent with hollow viscous perforation or haemoperitoneum.

Those with stable haemodynamics, without signs of peritonitis, or gut evisceration were considered for selective non-operative management (SNOM). This entails close monitoring and serial clinical and radiological abdominal examinations of patients. Failure of SNOM occurs if a patient previously on SNOM protocol eventually undergoes operation due to deteriorating/non-improving clinical status.

Furthermore, additional information on intra-operative findings and organs injured (for patients that had surgery), associated extra abdominal injuries and complications arising from management of the patients were entered into the data sheet. The data generated were analyzed using the descriptive statistics of Statistical Package for
Social Sciences (SPSS) version 20.0 (IBM incorporated). The morbidity and mortality rates were the main outcome measures.

\section{Results}

There were 96 victims with abdominal injuries during the study period from 2015 to 2018. Of these, 46 (47.9\%) patients had penetrating abdominal injuries, while 50 (52.1\%) patients had blunt trauma. The ages of the patients ranged from 17-72 years (mean $=34.2 \pm 10.8$; median $=$ $34)$. The majority of patients $(n=42 ; 91.3 \%)$ were males, while $4(8.7 \%)$ were females. The male-to-female ratio was about 11:1. Figure 1 reveals that the highest incidence of PAIs was seen in year 2018; while the age group most involved was within the $4^{\text {th }}$ decade of life (Figure 2).

The different mechanisms of penetrating abdominal injuries encountered in the study are shown in Table 1. Most PAIs ( $n=28 ; 60.9 \%)$ were due to gunshot followed by stab injuries in $12(26.1 \%)$ patients from either armed robbery attacks or violence. According to the locations of PAI, 33 (71.7\%) involved anterior abdomen, 3 (6.5\%) were trans-pelvic, while $5(10.9 \%)$ each were in the thoracoabdominal region and posterior abdomen or flank, respectively.

Of the 4 females affected, 3 had unsafe abortions, while one was due to gunshot. Presentation at the accident and emergency department was within 0.5-96 hours (mean $6.5 \pm 18.6$ ). A patient who had unsafe abortion was referred

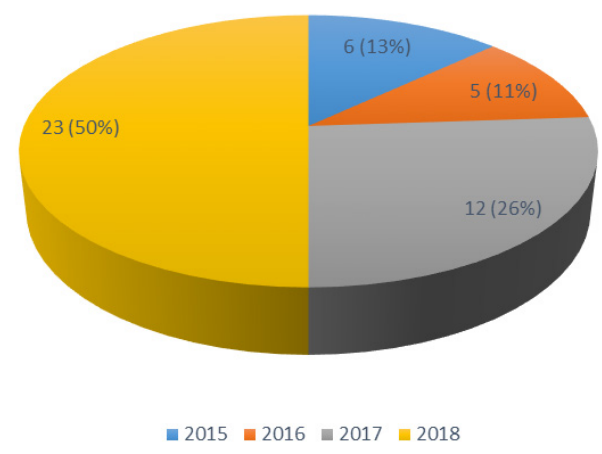

Figure 1. Incidence of PAI per year.

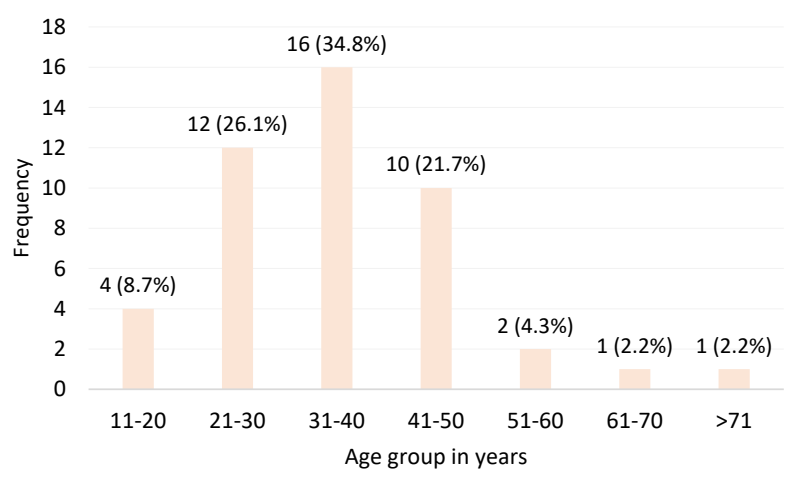

Figure 2. Age distribution of patients. 
Table 1. Mechanisms of injuries

\begin{tabular}{lcc}
\hline Mechanism of injury & Frequency & Percent \\
\hline Gunshot & 28 & 60.9 \\
Stab & 12 & 26.1 \\
Unsafe abortion & 3 & 6.5 \\
Road traffic injury & 2 & 4.3 \\
Fall on object (impalement) & 1 & 2.2 \\
\hline Total & 46 & 100.0 \\
\hline
\end{tabular}

to the center after 96 hours of injury.

Thirty-eight ( $\mathrm{n}=46 ; 82.6 \%)$ patients required exploratory laparotomy with/without other surgical procedures. The pattern of intra-abdominal and associated-visceral injuries is shown in Table 2 . The majority $(89.5 \% ; n=38)$ of the injuries affected the gastrointestinal system in which small bowel perforations predominated. Solid organ injuries were only seen in $3(7.9 \%)$ patients. Eight $(21.1 \%)$ patients had injuries involving two or more structures, while 8 patients also had extra-abdominal injuries all resulting from gunshot wounds.

The different surgical procedures are shown in Table 3. Simple bowel repairs were done for most perforations, while resection with primary anastomoses was performed in multiple perforations involving a contiguous bowel segment. Colonic injuries with gross peritoneal soilage required a diverting colostomy. One of the 8 patients with multiple gunshot injuries and perforation of the lower ureter had ureteroneocystostomy in addition to

Table 2. Intra-abdominal and associated injuries

\begin{tabular}{lc}
\hline & No. (\%) \\
\hline Intra-abdominal injury & \\
Omentum/small bowel evisceration & $4(10.5)$ \\
Stomach perforation & $3(7.9)$ \\
Retroperitoneal haematoma & $2(5.3)$ \\
Small bowel perforation & $16(42.1)$ \\
Caecum & $2(5.3)$ \\
Transverse colon & $2(5.3)$ \\
Sigmoid colon & $4(10.5)$ \\
Rectum & $1(2.6)$ \\
Ureter (lower part) & $1(2.6)$ \\
Kidney & $1(2.6)$ \\
Liver & $2(5.3)$ \\
Total & $38(100)$ \\
Associated injuries & \\
Chest (rib fracture, haemothorax, pneumothorax) & $5(62.5)$ \\
Upper limb laceration & $2(25.0)$ \\
Soft tissue & $1(12.5)$ \\
\hline
\end{tabular}

*Eight patients had multiple visceral injuries.
Table 3. Surgical procedures performed

\begin{tabular}{lcc}
\hline Procedures* $^{*}(\mathbf{n} \mathbf{3 8})$ & Frequency & Percent \\
\hline Simple closure of perforations & 11 & 28.9 \\
Bowel resection + primary anastomosis & 14 & 36.8 \\
Large bowel repair + diverting colostomy & 6 & 15.8 \\
Right hemicolectomy & 1 & 2.6 \\
Partial omentectomy & 2 & 5.3 \\
Hepatorrhaphy & 1 & 2.6 \\
Ureteroneocystostomy & 1 & 2.6 \\
Exploratory laparotomy only & 2 & 5.3 \\
Total & 38 & 100.0 \\
\hline
\end{tabular}

*Eight patients had multiple procedures including 4 closed thoracostomy tube drainage (CTTD).

other procedures. A patient with stab wound had a nontherapeutic laparotomy giving a negative laparotomy rate of $2.6 \%$. Eight $(17.4 \%)$ patients: 5 with stab and 3 with tangential gunshot injuries had SNOM. The duration of hospital stay was $1-58$ days (mean $12.7 \pm 10.5$ ). Five of the patients who had SNOM were observed for 24 hours. Thereafter, they were discharged home when there was no evidence of peritonitis or haemodynamic derangement. There was one case of failed SNOM and in this case, the surgery was delayed for up to 26 hours. The patient had gunshot injury to the right upper abdominal quadrant, and initial abdominal ultrasound scan done was adjudged unremarkable, but the patient subsequently developed peritonitis.

Seven (15.2\%) patients developed complications in this study. A patient (2.2\%) developed wound dehiscence and enterocutaneous fistula, while $5(10.8 \%)$ had superficial surgical site infections. They all did well on antibiotics and regular wound dressing and were successfully discharged. Three patients with multiple visceral injuries died giving a mortality rate of $6.5 \%$ (Table 4). Multiple injuries contributed to the morbidity and mortality recorded in some of the patients. Patients had an average follow-up period of 10 months.

\section{Discussion}

The burden of PAI appears to be on the increase in our setting, when compared to a previous study on abdominal trauma (47.9\% vs. $27.9 \%)$ (9). This increase may not be unconnected with rapid urbanization, civil unrest, political thuggery, and armed robbery attacks worsened by increased rate of unemployment. Our findings revealed that $50 \%$ of PAI occurred in the year 2018 which was an election year. Most of the injuries were from political violence and armed robbery attacks. Young people in their thirties (median $=34$ years) were mostly affected and the majority $(n=32 ; 69.6 \%)$ were in the first four decades of life. This finding was similar to reports by other authors worldwide (1,6,9-11). This subset of the population (age 
Table 4. Disposition of mortality cases

\begin{tabular}{|c|c|c|c|c|c|}
\hline Age & Sex & Type of injury & Operative findings & Treatment & Duration of admission \\
\hline 34 & Male & Gunshot & $\begin{array}{l}\text { Haemoperitoneum, mesenteric tear, ileal } \\
\text { and sigmoid perforations. }\end{array}$ & $\begin{array}{l}\text { Repair of mesenteric tear, ileal } \\
\text { resection with primary anastomosis, } \\
\text { sigmoid resection, Hartmann's } \\
\text { operation }\end{array}$ & 2 days \\
\hline 48 & Male & Gunshot & $\begin{array}{l}\text { Rib fracture, renal vein injury, } \\
\text { haemoperitoneum, gallbladder transection, } \\
\text { transverse colonic perforations }\end{array}$ & $\begin{array}{l}\text { Vascular repair, partial } \\
\text { cholecystectomy, transverse colonic } \\
\text { resection with colostomy }\end{array}$ & 9 days \\
\hline 33 & Male & Gunshot & $\begin{array}{c}\text { Haemoperitoneum, multiple ileal and } \\
\text { caecal perforations, massive retroperitoneal } \\
\text { haematoma }\end{array}$ & $\begin{array}{l}\text { Ileal resection with anastomosis, } \\
\text { closure of caecal perforations }\end{array}$ & 12 hours \\
\hline
\end{tabular}

group 31-40 years) is the most physically and socially active and the economically productive workforce. The attendant negative economic impact could be very significant to the families, communities and the nation at large.

The higher frequency recorded in males $(n=42 ; 91.3 \%)$ in the present study also conforms to findings from both local and international studies $(1,6,7,9-11)$. This could be explained by more frequent involvement of males in the act of violence and criminal activities as well as having greater mobility. The latter may be associated with their roles as breadwinners of their families. Although PAI is not uncommon in paediatric age groups $(10,11)$, this study did not record any. This may be due to the peculiarities of the population and disease epidemiology during the study period.

The causes of PAIs as well as the rates of occurrence vary from one region to the other. Abdominal gunshot and stab injuries were major causes in this study. Both mechanisms were responsible for approximately $87 \%$ of all cases presented; with gunshot injuries being the most frequent mode of injury (in $60.9 \%$ of cases). This is similar to $57 \%$ reported by Dogo et al (12) in northern Nigeria. However, this rate was higher than $44.4 \%, 20.7 \%, 38 \%$ and $16.5 \%$ reported by Edino (5), Ohene-Yeboah et al (6), Asuquo et al (10) and Omer et al (11) respectively; but less than $79.8 \%$ reported by Monzon-Torres and OrtegaGonzalez (13) in South Africa. In Nigeria, there appears to be a rise in the rate of PAI $(14,15)$. Increased spate of armed robbery as a result of unemployment and violence during political rallies might be contributing factors. Also, ethno-cultural conflicts as lately seen between nomadic herdsmen and indigenous farmers in various parts of Nigeria and the activities of terrorist groups like the Boko Haram sect are also contributory. Our investigation shows that $75 \%$ of the PAI in females were due to illegal and unsafe abortions, while the remaining one (25\%) was due to armed robbery attack. This relatively higher proportion of females with PAI following abortion practices further buttresses its status as a major public health concern in Nigeria. The Nigerian law prohibits induced abortion for socio-cultural and religious reasons. Thus, the majority of terminated pregnancies are clandestinely done, often by quacks or unskilled health services providers with attendant high complication rates (16).

The anterior abdomen was commonly affected in $71.7 \%$ of cases which was similar to $72.9 \%$ reported by Omer et al. This can be explained by the higher proportion of patients who were victims of robbery or other violenceassociated events with the victims facing their assailants or engaged in a fight. Associated extra-abdominal injuries are not uncommon in PAI. Five $(62.5 \%)$ patients had associated chest injuries all resulting from gunshot, and $80 \%$ of these required closed thoracostomy tube drainage. This higher rate of chest injuries has been reported by some other authors $(6,10)$. Injuries involving the lower part of the chest or the upper abdomen have the tendency to involve not only structures in the chest but also some other intra-abdominal structures; this is due to the unique position and attachments of the diaphragm which separates these two regions. Thus, in injuries to lower chest or upper abdomen, intraperitoneal organs and/or diaphragmatic injuries should be suspected alongside the breech of the pleural and lungs. Hence, thoracoabdominal injuries may be associated with chest pathology in the form of haemothorax, pneumothorax or diaphragmatic laceration. In this study, there was no diaphragmatic injury despite the presence of other chest injuries. However, it is very important to suspect and evaluate patients for diaphragmatic injuries when patients have penetrating thoracoabdominal injuries; so as to prevent morbidity and possible mortality that could be associated with missed diagnosis.

Small bowel perforations (42.1\%) followed by large bowel perforations (23.7\%), both accounting for $65.8 \%$, were the most common injuries. Although there is a slight regional variation in the rates of visceral injuries, gastrointestinal tract injuries were the most common in which small bowel perforations were mostly reported $(6,10,11,13,17)$. The higher tendency of small bowel injury could be due to the larger length and distribution within the intra-abdominal (peritoneal) space. Solid organ injuries in this study only involved the liver and the kidney in $7.9 \%$ as there was no splenic injury. The rate of solid organ involvement 
reported by Omer et al was $22.9 \%$. Compared with blunt abdominal trauma where there was preponderance of splenic injuries $(5,9,12,18)$, the spleen appears to be less injured in PAI; going by the findings in this study.

The majority $(n=38 ; 82.6 \%)$ of patients had operative treatment. This rate is within a range of $80.5 \%-86.2 \%$ reported by other authors recently $(6,10,11)$. The practice of mandatory laparotomy used to be the standard of care in times past until this was challenged by Shaftan (19) in 1960 and this has significantly reduced negative laparotomy rates and the concomitant morbidities of surgical intervention. Eight (17.4\%) patients in this series were selectively managed nonoperatively. Of 12 patients with stab wounds, $5(41.7 \%)$ did not require surgical operation. Although, they all had local wound exploration with evidence that the wound did not penetrate the anterior fascia of the abdominal wall. There was no significant visceral injury in one of those who had exploratory laparotomy, thereby giving a negative laparotomy rate of $2.6 \%$. Successful non-operative management is hinged on careful patient selection, serial and meticulous physical examination preferably by the same surgeon which on its own is more demanding in a setting where there is dearth of diagnostic facilities. Similarly, three (10.7\%) patients with gunshot wounds also had SNOM. SNOM initially advocated for stab and low energy transfer injuries is increasingly gaining acceptance even for gunshot wounds amidst unresolved controversies in its applicability in missile injuries. The findings from this study further attest to the fact that the concept of "selective conservatism" is practicable for both stab and gunshot abdominal injuries in low- and medium-income countries like ours when there is required expertise $(7,8,20)$.

There is gross deficiency in surgical capacity in Africa, which includes lack of modern imaging facilities in many hospitals (21). Apart from chest radiography and ultrasonography, laparoscopy and computerized tomography which are modern ancillary tools for accurate detection of intra-abdominal injuries are not available in our hospital. Therefore, a lower threshold for surgical exploration by the surgeons practicing in such resourcechallenged facilities is still not unreasonable: "better to look and see, than to wait and be sorry"; hence non-operative management of PAI would be an exception rather than the rule.

The complication rate from this study was $15.2 \%$ and was mostly wound infection in $10.8 \%$. This is not unusual as most patients with multiple bowel perforations had gross intraperitoneal contamination. One patient with abdominal gunshot injury involving the right upper quadrant, whose initial abdominal ultrasound scan was unremarkable, had a failed SNOM. Surgical intervention was delayed for 26 hours in a bid to avoid negative laparotomy. Post-surgery, he developed surgical site infection and stayed a further 18 days on admission. Thus, the surgeon needs to critically appraise the relative risk of SNOM and complications arising from delayed laparotomy. Two patients developed wound dehiscence and enterocutaneous fistula. Both of them were managed conservatively (non-operatively), with the latter having the longest hospital stay (58 days).

The overall mortality of $6.5 \%$ in our center falls within the range of $4.4-10.3 \%$ reported by earlier authors (6, $10,11,22)$, but lower than $16.8 \%$ by Monzon-Torres and Ortega-Gonzalez (13). The mortalities from our center were only from gunshot injuries. When considered based on this mechanism alone, $10.7 \%$ deaths resulted from gunshot wounds. This is close to $14.1 \%$ in a study by Ohene-Yeboah et al (6) in Ghana and $12.0 \%$ reported by Feliciano et al (23) in a larger gunshot series. Thus, this study affirms that gunshot wounds, being a high impact and high energy injuries, have more devastating effects, and are usually associated with more mortalities than other causes of PAI. Hence, efforts to control proliferation of arms and access to them within the populace could likely reduce the rising trend of PAI and mortality from it.

\section{Conclusion}

There is a high and increasing rate of PAI in our practice. Most injuries were from violence-related events and affected males at the prime time of their age. Most female injuries were from unsafe abortion. Mortalities were from gunshot injuries, and non-operative management was feasible and practicable in a few carefully selected cases of PAI. Efforts at gun control and promotion of peaceful conflict resolution would help abate the rising tide of PAI.

\section{Authors' contributions}

JGO and ACE conceived the study and were involved in the design and data collection. JTI and OKW were involved in the data collection, collation and statistical analysis. JGO and ACE made the final draft of the manuscript. All the authors read and approved the final manuscript.

\section{Ethical issues}

Approval for the study was granted by the ethics and research committee of the Ekiti State University Teaching Hospital (EKSUTH), Ado-Ekiti (Ethical Code Number: EKSUTH/A/67/2015/10/011).

\section{References}

1. Aldemir M, Tacyildiz I, Girgin S. Predicting factors for mortality in the penetrating abdominal trauma. Acta Chir Belg 2004; 104(4): 429-34.

2. Mohammed AZ, Edino ST, Ochicha O, Umar AB. Epidemiology of gunshot injuries in Kano, Nigeria. Niger J Surg Res 2005; 7(3-4): 296-9. doi: 10.4314/njsr.v7i3.12301.

3. Udosen AM, Etiuma AU, Ugare GA, Bassey OO. Gunshot injuries in Calabar, Nigeria: an indication of increasing societal violence and police brutality. Afr Health Sci 2006; 6(3): 170-2. doi: 10.5555/afhs.2006.6.3.170.

4. Etonyeaku AC, Ogundipe KO, Omotola CA, Ishola OJ, Olasehinde O, Obonna GC. Spectrum of Gunshot Injuries 
in Civilian Practice at a Tertiary Hospital in a Semi-rural Community in Nigeria. East Cent Afr J Surg 2014; 19(1): 83-9.

5. Edino ST. Pattern of abdominal injuries in Aminu Kano Teaching Hospital, Kano. Niger Postgrad Med J 2003; 10(1): 56-9.

6. Ohene-Yeboah M, Dakubo JC, Boakye F, Naeeder SB. Penetrating abdominal injuries in adults seen at two teaching hospitals in ghana. Ghana Med J 2010; 44(3): 1038 .

7. Navsaria PH, Berli JU, Edu S, Nicol AJ. Non-operative management of abdominal stab wounds--an analysis of 186 patients. S Afr J Surg 2007; 45(4): 128-30, 32.

8. Tsikitis V, Biffl WL, Majercik S, Harrington DT, Cioffi WG. Selective clinical management of anterior abdominal stab wounds. Am J Surg 2004; 188(6): 807-12. doi: 10.1016/j. amjsurg.2004.08.046.

9. Olaogun JG, Akute OO, Etonyeaku AC, Ige JT, Ajibola DB, Afolayan JM, et al. Abdominal trauma in a semi-urban tertiary health institution. J Emerg Pract Trauma 2018; 4(2): 67-72. doi: 10.15171/jept.2018.07.

10. Asuquo ME, Umoh MS, Nwagbara V, Ugare G, Agbor C, Japhet E. Penetrating Abdominal Trauma: Experience in A Teaching Hospital, Calabar, Southern Nigeria. International Journal of Clinical Medicine 2012; 3(5): 426-30. doi: 10.4236/ijcm.2012.35079.

11. Omer MY, Hamza AA, Musa MT. Penetrating Abdominal Injuries: Pattern and Outcome of Management in Khartoum. International Journal of Clinical Medicine 2014; 5(1): 18-22. doi: 10.4236/ijcm.2014.51004.

12. Dogo D, Yawe T, Hassan AW, Tahir B. Pattern of abdominal trauma in North Eastern Nigeria. Niger J Surg Res 2000; 2(2): 48-51. doi: 10.4314/njsr.v2i2.12184.

13. Monzon-Torres BI, Ortega-Gonzalez M. Penetrating abdominal trauma. S Afr J Surg 2004; 42(1): 11-3.
14. Akhiwu WO, Igbe AP. Fatal gunshot injuries in Benin City, Nigeria. Med Sci Law 2013; 53(4): 199-202. doi: 10.1177/0025802413483718.

15. Osime C, Kpolugbo J. Pattern and outcome of penetrating injuries in Irrua, a sub-urban community in Nigeria. Afr J Trauma 2004; 2: 40-2.

16. Fawole AA, Aboyeji AP. Complications from unsafe abortion: presentations at Ilorin, Nigeria. Niger J Med 2002; 11(2): 77-80.

17. Tillu N, Rathod C, Kumar M, Kumar V. A study to assess the 30 days outcome of penetrating injuries to the abdomen. Int Surg J 2017; 4(1): 64-74. doi: 10.18203/23492902.isj20164053.

18. Ayoade BA, Salami BA, Tade AO, Musa AA, Olawoye OA. Abdominal Injuries in Olabisi Onabanjo University Teaching Hospital Sagamu, Nigeria: Pattern and Outcome. Niger J Orthop Trauma 2006; 5(2): 45-9.

19. Shaftan GW. Indications for operation in abdominal trauma. Am J Surg 1960; 99: 657-64. doi: 10.1016/00029610(60)90010-6.

20. Van Brussel M, Van Hee R. Abdominal stab wounds: a fiveyear patient review. Eur J Emerg Med 2001; 8(2): 83-8.

21. Olaogun JG, Popoola SO, Olatunya OS, Oluwadiya KS. Where there is no specialist: surgical care in a secondary health facility in a developing country. Egypt J Surg 2014; 33(4): 223-7. doi: 10.4103/1110-1121.147596.

22. Lone GN, Peer GQ, Warn KA, Bhat AM, Warn NA, Bhat MA. An experience with abdominal trauma in adults in Kashmir. JK Pract 2001; 8(4): 225-30.

23. Feliciano DV, Burch JM, Spjut-Patrinely V, Mattox KL, Jordan GL Jr. Abdominal gunshot wounds. An urban trauma center's experience with 300 consecutive patients. Ann Surg 1988; 208(3): 362-70. doi: 10.1097/00000658198809000-00014. 